\title{
ENTRE A ESCRITA E A EXPRESSÃO: VIAS PARA A PRODUÇÃO DE CONHECIMENTO ${ }^{1}$
}

\author{
Tania Mara Galli Fonseca* \\ Marcele Pereira da Rosa Zucolotto" \\ Sara Hartmann"
}

\begin{abstract}
RESUMO. A escrita é a forma majoritariamente utilizada para produção e divulgação de conhecimentos. O seu papel na comunicação já é um consenso. No que diz respeito à sua parte na criação, entretanto, a escrita abre um campo de possibilidades das quais a universidade faz um aproveitamento, no mínimo, exíguo. Este artigo pretende adentrar um espaço de diluição das figuras tradicionais da escrita - como o eu que escreve e os regimes imutáveis de significação - a fim de espreitar a expressão, com a crença na possibilidade de reunir as funções da ciência com os afectos da escritura. A contribuição à escrita acadêmica assemelha-se, então, a um sopro de inesperado quando tudo parece estar demasiado claro. É o aparecimento de inúmeras possibilidades de experiências com a palavra, através das quais o escrever acadêmico pode investigar suas zonas informes.
\end{abstract}

Palavras-chave: Escrita; expressão; experimentação.

\section{BETWEEN WRITING AND EXPRESSION: PATHWAYS FOR THE PRODUCTION OF KNOWLEDGE}

\begin{abstract}
Writing is the most commonly used form in production and dissemination of knowledge. Its role in communication is already a consensus. Regarding to its part in creation; however, writing unfolds to a vast range of possibilities, of which the university usage is, at least, meager. This article aims at entering a space of dilution of the traditional figures of writing - for instance, the " $\mathrm{I}$ " that writes and the immutable systems of meaning - in order to stalk the expression, with the belief in the possibility of merging functions of science and the affection of writing. The contribution to academic writing resembles, thus, to an unexpected blow, when everything seems too settled. It is the appearing of innumerous opportunities of experience with words, through which the academic writing can investigate its own shapeless areas.
\end{abstract}

Key words: Writing; expression; experimentation.

\section{ENTRE LA ESCRITURA Y LA EXPRESIÓN: VÍAS PARA LA PRODUCCIÓN DE CONOCIMIENTO}

RESUMEN. La escritura es la forma principal utilizada para la producción y difusión de conocimientos. Su papel en la comunicación es ya un consenso. Por su parte en la creación, sin embargo, la escritura se abre a un campo de posibilidades que la Universidad hace una recuperación al menos escasa. Este artículo pretende introducir un espacio de diluición de las figuras tradicionales de escritura - como el yo que escribe y los regímenes inmutables de significado - a fin de escuchar la expresión, con la creencia en la posibilidad de reunir las funciones de la ciencia con la calidez de la escritura. La contribución a la escritura académica es similar, pues, un golpe inesperado cuando todo parece ser demasiado claro. Es la aparición de numerosas posibilidades de experimentar con la palabra, a través del cual la escritura académica puede investigar sus zonas informes.

Palabras-clave: Escritura; expresión; experimentación.

\footnotetext{
Apoio: Capes.

Psicóloga. Doutora em Educação pela Faculdade de Educação da Universidade Federal do Rio Grande do Sul, pesquisador CNPQ e FAPERGS, coordenador do Diretorio de pesquisa Corpo, Arte e Clínica nos modos de trabalhar e subjetivar/ CNPQ, professora do Programa de Pós-Graduação em Psicologia Social e Institucional da Univesidade Federal do Rio Grande do Sul, Brasil

\# Psicóloga. Mestre e Doutoranda em Psicologia Social e Institucional pela Universidade Federal do Rio Grande do Sul, Brasil.

II Psicóloga. Mestre em Psicologia Social e Institucional pela Universidade Federal do Rio Grande do Sul, Brasil.
} 
escrever

os dedos

os dedos

estranhos

encontros sem fim

acolhidos, ou despejados

sem dó

das linhas adentradas

feitas vibração

não haverá volta

que se morra pois

pertence

à terra

ou nada germina

nunca só, ou lá

nas palavras

somos material

dias corridos

mãos às voltas

em busca de abrigo

quando ao que se chega

é um descampado perigo

perdido

mas aquecido

entre os tropeços

Escreve-se. Escreve-se para, escreve-se com, escreve-se através... Diversas propostas acompanham a escrita, no entanto, ao escrever não se trata de encontrar resolução possível, endereçamento acertado, razão maior. Escrevendo, nada parece estar bemassentado. Toma lugar, justamente, uma andança desconsolada ao longo da procura por pontos de ancoragem, enquanto se desmancham as referências. Pretendemos aqui atravessar um caminho, deixando aparecer que é pela diluição que se encontra ainda um fino fixo qualquer.

Trata-se aqui de uma proposta do escrever que indissocia razão e sensível. A produção de conhecimento, assim, vem de forma vital, e não exclusivamente racionalizada. Por meio de um texto que está intimamente ligado a questões que movimentam toda escrita, não se quer estar compromissado com nenhuma forma transcendente ou anteriormente fundada. Texto a compor com as formas, que quer fazer aparecer conhecimento lá onde não se espera.

A expressão, com Gilles Deleuze (1997, 1969/2007) e Maurice Blanchot (1953/2001, 1959/2005), vem encontrar-nos na escrita. Em ambos os casos, trata-se do desenrolar sem fim de uma experimentação, em que a substância da vida desenvolve a si mesma no preciso movimento em que amplia toda possibilidade de existência.

Viver a linguagem é travar relação com ela: poder instalar-se, desabrigar-se, arrancar caminho, pedir para sair, ser derrubado; sufocar a linguagem mas ao mesmo tempo ser asfixiado por ela. Torcê-la. Fazer com que diga algo que já não se entende. Fazer com que diga algo do qual se tenha medo. Arrancar sua própria pele. Destelhar-se através das palavras. Travessia. Queda-d'água. Cambaleio no escuro. Prática de linguagem que só consegue acolher ventos, silêncios e chuvas. No poema "Palavras", Manoel de Barros defende-se da acusação feita de que ele seria um desestruturador da linguagem:

Vejamos: eu estou bem sentado num lugar. Vem uma palavra e tira o lugar de debaixo de mim. Tira o lugar em que eu estava sentado. Eu não fazia nada para que a palavra me desalojasse daquele lugar. E eu nem atrapalhava a passagem de ninguém. Ao retirar o de debaixo de mim o lugar, eu desaprumei. Ali só havia um grilo com a sua flauta de couro. $\mathrm{O}$ grilo feridava o silêncio. Os moradores do lugar se queixavam do grilo. Veio uma palavra e retirou o grilo da flauta. Agora eu pergunto: quem desestruturou a linguagem? Fui eu ou foram as palavras? E o lugar que retiraram de debaixo de mim? Não era para terem tirado a mim do lugar? Foram as palavras pois que desestruturaram a linguagem. E não eu. (Barros, 2000, p. 57)

O poeta coloca em questão algo de nossa atualidade: muitas vezes temos a sensação de que as pessoas não podem ou estão impedidas, em alguma instância, de se exprimirem, inclusive por meio da escrita. Não obstante, os equívocos logo começam a surgir: tanto a escrita quanto a expressão, não tratam de narrar uma experiência, de dar uma versão dos fatos, de comunicar um esconderijo de si. Se há algo hoje que toda e qualquer pessoa pode fazer, tomando como objeto uma relação, um trabalho, uma viagem, é escrever um livro ou artigo por achar tais temas suficientes para tal. É porque entendem que suas vidas pessoais, que suas experiências particulares merecem uma escrita. Entendem a escrita como algo que retira seu fôlego do vivido; no entanto, o vivido, o pessoal, muito pouco ajudam a escrever. O que existe compõe menos linhas de escrita do que o que subsiste. Este sim, parece escrever sem se cansar.

Dessa forma, o que está em jogo na escrita não remete a um indivíduo, espectro de identidade no qual se busca, quase sempre inutilmente, a origem do escrever. Aqui aparece o que consideramos outro equívoco: quem escreve não é um eu, a expressão não é de um sujeito. Parece que a própria linguagem faz desvanecer esse elemento, na medida em que provoca 
aparecimentos e desaparecimentos da figura de quem escreve, de acordo com a artimanha com a qual se faz uso dela. Como poderia alguém ser o responsável por desestruturar uma linguagem, fazê-la experimentar seus limites? A ideia soa mais estranha quando pensamos no escritor como esse que se mete com as palavras e, quando menos espera, tem um lugar retirado debaixo de si. Se a escrita é antes expressão, certamente não se pode dizer que seja a expressão de um eu, forte e estruturante, denso e consistente, ou mesmo pobre e incoerente. Nada de eu, nada de sujeito. A escrita de que falamos aqui é simplesmente expressão, expressão como produção. Produção singular, escrita desfiliada. Movimento de um afeto que não se deixa fisgar, que não se cansa de se esvoaçar. Produção inominada em obtuso apetite. $\mathrm{O}$ que se produz, afinal, e se deixa expressar pela escrita, é antes um fluxo a se remexer para todos os lados e friccionar pacotes abarrotados de potência, de intensidade impecável. Produção de permanência apenas da transição e do movimento. Nem mais, nem menos. Deleuze (1997), em seus trabalhos, insiste em mostrar quanto as palavras, quando se escreve, não estão a serviço de um ego, não se fazem expressão dos desejos do escritor, nem a ele conseguem mais estar vinculadas. As palavras expressam. Simplesmente.

Assim, tão perto daquelas palavras de dominação, daquelas palavras que organizam a linguagem, talvez mesmo saídas de suas próprias ranhuras, produzem-se aquelas que fazem da escrita algo em que o homem não impera, nem mesmo o escritor. A escrita como expressão produtiva arranca a possibilidade de supremacia, e fala uma

outra fala: a que não dá nada, nada traz senão solidão, retirada, separação; ela é sem conhecimento, sem resultado; aquele que a pronuncia não a conhece, conhece apenas seu peso, sua pressão, sua exigência infinita; fala que não é humana, que não vem ao homem capaz, mas àquele que se vê de repente sozinho, desligado, recusado, abandonado (Blanchot, 1959/2005, p. 109).

Abandonado de si, de suas linhagens, de suas angústias, de suas antigas existências, de seus pequenos universos passíveis de recordação. Abandonos ao infinito como a condição da experiência de dilatação de rumores hábeis à escrita, dispondo-a a um campo de excessos, a um torvelinho de velocidades variáveis e de teores salientes de êxtase. Abandonar-se para iniciar outros rumos, vidas, ventos, guaridas, para começar novos percursos em outros excessos. Contínuos recomeços nunca plagiados, mas sempre começados pelo meio, ou ao léu, mas sem dar espaço para adormecer o movimento, para a paralisação insípida e cansativamente inerte.

Nessa escrita, então, há uma diluição da origem, que extravasa qualquer material pessoal. O que se dá não tem população de referência, mas cria possibilidades de vida não imaginadas, ainda impossíveis e incertas, e por isso, lançadas impiedosamente à sua própria sorte. Com a força que lhes couber, tais possibilidades já não encontram um reduto de sentido em mais nada nem ninguém, somente potência de proliferação.

Se já não se trata da expressão de alguém, mas da expressão como pura produção, talvez seja o caso de um silêncio que mereça ser dito, escrito por inteiro. Um vazio de forma que mereça muitas palavras por extenso, expressas ao máximo de seus contornos e detalhes. Escrever como a fenda pela qual cruzam as passagens de experimentações, já que se faz corresponder tanto o falar e o ver - como nos lembra Deleuze (1988) através de Foucault, é como se ambos fossem uma mesma ação, logo não há mais nada a dizer, nada que já não esteja presente em imagens ou símbolos. Será preciso dizer o que, absolutamente, não se pode ver. No contrafluxo da imagem que encerraria em si mesma a possibilidade de dizer, trata-se de forçar a vista e a linguagem junto àquilo que escapa às palavras, e mesmo a qualquer forma de representação. Exercício que já soa banal, deglutido e regurgitado por toda parte, mas que deve se armar justamente contra o "já visto", insistir em explorar vacúolos de silêncio sem extirpar-lhes o estatuto de recolhimento inerente. Ou melhor, testemunhar pela inelutabilidade de uma desaparição das coisas e de si no que se escreve. Um inexpiável distanciamento.

Também não incorre representar o mundo, pois que já não há regras universais a que a linguagem, pensada como um conjunto de signos que servisse de instrumento para a comunicação, tendo o compromisso de manter uma igualdade com a realidade, se colocasse como mera serva na representação das coisas. A linguagem passa a valer por si mesma, não representando nem se reportando mais ao homem ou a Deus, mas a um espaço em que a palavra se multiplica por si mesma, num desdobrar-se infinito (Blanchot, 1953/2001). Nas palavras de Henry Miller (1964), a escrita não encontra recompensa a não ser em si mesma, enquanto ato compulsivo e deleitável, e não em um jogo jogado de acordo com certas regras, como as da representação. Passando a valer por si mesma, a escrita cria sua própria realidade e põe em questão o quanto a linguagem já não depende do indivíduo, nem de valores divinos para 
existir. Ao contrário, ela se dá justamente quando da dissolução do que há de humano, de identidades ou de quaisquer outros lugares fixos (Deleuze, 1997).

Nos desaparecimentos do que há de densidade, as linhas de escritas começam a expressar, mas apressam-se em expressar apenas intermitências de vida. Sementes de chuva. Excessos. Não há posse possível. O fim de partida apenas inicia; e então mais uma linha é arrancada de seu sossego, junto de outras, sem superioridade, sem ainda retenção. É uma noite sem fim que abastece o silêncio. E o silêncio permanece a escrever. Restam os ouvidos da fabulação quando os ouvidos do homem se cobrem.

Expressar por fábulas não faz menção a um mundo suprassensível, anterior ou mesmo posterior ao mundo em que vivemos, como a escapar dele através de sonhos, alucinações ou utópicas fantasias que negam a vida e o que se tem. Ao invés disso, fabular como expressão remete a este mundo mesmo em que vivemos, criando as condições para que outros tantos sejam possíveis, e estes, por sua vez, mantenham a capacidade de desencadear as transformações do mundo existente. Não precisamos recusar a vida em que vivemos, mas nem resignarmo-nos a ela.

Traçando considerações sobre as experiências literárias na América Latina, Pellejero (2008) mostra o quanto estas puderam esboçar um mapa das situações aqui vividas e, além disso, reagir a elas; mas nestas saídas e evasões literárias, algumas se deram de forma mágica que, apesar de "levantar os preceitos do realismo contemporâneo e as impossibilidades que nos assediam na História" (Pellejero, 2008, p. 71), falhavam na hora de propor uma alternativa, já que "a saída implica uma transformação que nos põe fora do mundo e que no grosso dos casos passa pela morte" (Pellejero, 2008, p. 71). Diferentemente dessa forma de realismo mágico na literatura latina, Pellejero (2008) encontra experiências literárias que, além de traçarem com rigor o mapa de nossas impossibilidades, projetam um plano de evasão pelo próprio exercício de expressão, que desdobra novos campos de possíveis. O exemplo encontrado por Pellejero (2008) é a obra El hablador, de Vargas Llosa, que não exige a harmonia religiosa ou uma morte decisiva como saídas para nossas impossibilidades, antes "enreda todas as histórias, fazendo com que seus elementos entrem numa zona de indeterminação, dentro da qual os condicionamentos históricos, os preceitos morais ou sociais e, em geral, a soma de todas as impossibilidades tendem a esbaterse" (Pellejero, 2008, p. 72). As saídas se colocam no campo mesmo das batalhas, no emaranhado delas, quando as situações fazem acreditar que as mudanças são impossíveis, exatamente quando todas essas impossibilidades em jogo começam a perder viço, a abandonar-se.

Expressar pela escrita, seja ainda pelas fabulações, traz as possibilidades de enredar as linhas de transformações, tornando-as espessas e intensas a ponto de conseguir torcer aquelas realidades $\mathrm{e}$ situações históricas que nos fazem crer que as mudanças não são mais possíveis.

Através da escrita-fábula não se expressam verdades universais, soluções categóricas ou definitivas para todo o mundo, mas estratégias singulares que servem e valem para um mundo, sendo que este mundo pode fazer dessas novas estratégias seu novo mundo, e a partir deste podem reinventar outros tantos. Assim ao escrever como expressão fabuladora, o que se tem não são colocações de um mundo que não existe, são, sim, afirmações de uma vida que consegue inoperar as hegemonias que imperam.

Tão logo a escrita põe-se a escrever, o que temos é uma vida em suas múltiplas linhas, um emaranhado delas, a dizer de uma potência transformadora; pois já não se trata, com efeito, de uma linha única de vida pessoal, real, do romancista a reescrever suas recordações, opiniões, reflexões que, partindo da perspectiva do indivíduo, de um jeito ou de outro, a ele retornam. Uma vida por escrito é uma vida singular, nem pessoal, nem geral, que não objetiva atingir o mais íntimo de alguém, a fim de ali ressoar; mas sim, desde este mais íntimo, alcançar a exterioridade que é o seu avesso, que toca a todos os íntimos, desfazendo seu fechamento sobre si.

De fato, Deleuze (1997) entende a literatura como um processo de produção sempre remetendo à vida, possibilitando-a. Literatura tendo mesmo sua definição - ou intenção - nesta possibilidade de vida. Diz o autor: "Escrever é um processo, ou seja, uma passagem de Vida que atravessa o vivível e o vivido" (Deleuze, 1997, p. 15). Ao fazer esse atravessamento, parece que a literatura deixa ver certo nó existente entre o que é vivível e o que (ainda) não é, ao modo das fabulações. É essa experiência, no sentido mais forte do termo, que faz da literatura um modo privilegiado de aproximação ao Exterior, ou seja, ao informe, ao espaço irredutível para o qual se remetem as forças que a tudo compõem (Foucault, 1990). Ou seja, falamos aqui de uma experiência marginal, em que toma lugar uma fala não institucional, eminentemente desgarrada, capaz de minar discursos. Assim, a literatura somente consegue liberar vida a partir do instante em que atinge certo aniquilamento de territórios fixos. Tal obscurecimento é o requisito 
indispensável para que o escrever se torne uma atividade vital, e não mera expressão de indivíduos personificados. Esta exigência fala de um processo mortuário de destruição de evidências, de territorialidades fortemente endurecidas, coaguladas, estabelecidas.

Radicalmente, trata-se de criar novas vidas. Fazer de si uma existência criativa, fazer-se enquanto algo é materializado, sem esperar que um outro opere em si o que não se é capaz de operar: é disso que se trata. Fazer-se com o que se tem, com o que se é capaz de fazer de si, levando-se aos confins da sua potência. Uma criação em ação e sem esperança, na medida em que esta quer dizer que não se é o que se gostaria de ser; já que os tempos são sempre ruins, é tornar-se imune, tornar-se o que é sempre capaz de fazer-se. Em última análise, não se trata de literatura, enquanto campo arraigado e enredado em fluxos de saber. Trata-se de ser artista continuamente, e finalmente não ser artista de maneira nenhuma, e sim, uma vida ao modo da obra de arte. Capaz de durar e inquietar todo olhar, de refutar toda vontade de supremacia; capaz de lançar questões sem resposta, de provocar desvios que não retornem a uma individualidade. Estamos novamente com Henry Miller (1964), que dizia não fazer obras de ficção, mas livros humanos, e pronto. Para ele, todo o resto é literatura, "E eu não estou interessado em literatura" (Miller, 1964, p. 102).

O que a escrita como expressão expressa é, com isso, um conjunto de singularidades que são totalmente indiferentes àquilo que já adquiriu uma forma atual, seja ela a de um indivíduo, de um objeto ou sujeito. Completa impessoalidade que destrói as pessoalidades. Impassível neutralidade que ignora segmentos em oposição, pois elas são sempre isto e aquilo, mais e menos. É agora a lógica do E que tem lugar, pois o E não é uma conjunção entre outras, mas a força destituinte do primado do É. O E traz a potência do que se passa entre os termos. Por isso uma expressão pode ser, num mesmo lance, coletiva e particular, perceptível e microscópica, sendo sempre impessoal e não subjetiva. É desconsiderando todos os opostos que a escrita como expressão vai assegurar sua neutralidade e indiferença quanto ao individual e ao geral.

No entanto, se a escrita não sustenta nenhum sujeito, objeto ou a forma estabelecida que for, de modo algum é por defeito ou carência, mas porque ela própria traz as condições de tudo possibilitar. São, antes, os objetos, atos e sujeitos que devem ser pensados em função da expressão. É precisamente na impassível neutralidade que surge a imensa potencialidade da escrita. É no neutro que surge a potência, na apatia que aparece a mais alta fecundidade. As singularidades que constituem a escrita, numa incrível neutralidade, desprezam todas as formas já existentes, e é por se instalar nesse hiato que tudo conseguem criar e produzir qualquer tipo de novidade, afinal, é quando as formas se dissolvem que só restam as forças com suas linhas de potencialidade e de intensidade.

A criação, então, só é possível porque a escrita traz uma expressão da pura potência. Da intensidade ao extremo. Variações extraordinárias, insensatas, desvairadas, fascinantes e extasiantes só se tornam possíveis porque a escrita é de uma expressão neutra e potente o suficiente. Neutra a ponto de ignorar e desfazer todas as formas em pleno pouso, organização e desgaste. E potente a ponto de tudo ser capaz de criar. Partículas de energia intensa começam a latejar tão $\operatorname{logo}$ as formas se desalojam de seus estados tão sólidos. E a escrita traz os estados gasosos ou tão rarefeitos a ponto de desmanchar o próprio papel.

Afinal, a escrita põe em jogo uma aspereza e uma indiferença surpreendentes. É dissolvendo quem escreve, é rompendo os órgãos do corpo, é exterminando territórios tão fixos, é destituindo a representação, que há então algo a ser escrito. É enquanto expressão que a escrita agrega dissolvência, incertezas, rescisões, ruínas e abandonos; mas enquanto a escrita for tratada como expressão, tal destruição não é maldade, nem falha ou equívoco. É, antes, a própria condição de criação, já que toda e qualquer invenção coloca essa destruição em questão, afinal, não há como criar algo novo e totalmente insólito sem que as formas antigas caiam por terra, em desuso, aos destroços, em abandono, em indiferença... liberando as forças que ali estavam aprisionadas. E a novidade pode, assim, reutilizar essas forças, fazendo com que entrem em relações com outras, antes distantes, antes sem conexão. A novidade, muitas vezes, passa a ser esse novo composto de linhas de forças, linhas de escrita. É que às vezes não se trata, com efeito, de inventar uma nova língua, mas de fazer tropeçar aquela mesma que temos, produzir um soluço na linguagem, um solavanco no andar contínuo e abatido das existências demasiado ensimesmadas.

A expressão que faz escrever vem de um tempo em transição, não ainda resolvido por uma adaptação do ser, fala de um entremodos, de um tempo em que a disposição é ainda no não disposto e o abrigo é na falta de forma. Desalojar-se de hábitos e ainda não conseguir fazer disso um hábito é o que faz o escritor. Deslizar pelo não assentável. Avolumar vozes não discerníveis, nem definitivamente cortantes pelos costumeiros modos de estar, mas vozes em 
murmúrios, em ruídos em que a vida se faz ímpeto. Vozerio em ecos, a precipitar sentidos, resquícios de singulares deslocamentos. Essas zonas de risco e de indiscernibilidade que, aos olhos tão demasiadamente humanos são tomadas por um perigo dilacerante, a escrita substitui por uma potência fecunda, de onde as palavras torcem o sentido e o fazem escrever ao incansável. Zonas de vizinhança com o alheio de si, redemoinho de estações onde os deuses confundem e alucinam as palavras. Escrever beirando os abismos, onde os ecos cortam os corpos e arrancam o que de órgãos havia.

É que escrever como expressão requer uma porosidade com o campo imprevisível do acaso, do fora, das velocidades incessantes... para dali construir novos elementos, outras linhas e linhagens de vida. São movimentos que envolvem certa tomada de desposição, um deslocamento, o colocar-se num lugar que não está previamente indicado.

Vimos o quanto a produção dessa porosidade como uma região de pura intensidade, que pode levar à criação, só se faz a partir do desmoronamento daquilo que há de estabelecido, mesmo aquilo que ainda há de colado e pronto em nossas maneiras de viver, de agir, de escrever. Escrever implica a morte do já incrustado em nós, morte esta que tudo arrebenta, que libera intensidades, morte de amor... "Só se deveria morrer por amor, e não de morte trágica. Só se deveria escrever por essa morte, ou deixar de escrever por esse amor, ou continuar a escrever, os dois ao mesmo tempo" (Deleuze \& Parnet, 1998, p. 64). Por meio da escrita é possível se deparar com uma vida brincando com a morte, exprimindo dela não só o sofrimento que ela pode exalar, mas também certa leveza, plenitude com a qual a vida pode dançar. Só esta morte por amor libera a mais alta potência de uma vida, o que implica o acesso àquela região de despersonalização.

Neste sentido, expressar, mesmo pela escrita, não significa acusar, lastimar ou prescrever, ordenar e receitar, mas derrubar barreiras que reprimem possibilidades outras, combater aquilo que não deixa a vida pulsar livremente. Abertura para o cristalino escoamento da vida, apontamento para infinitas possibilidades de vida. Subterfúgios vitais. Pois escrever é dar margem a que mundos possam ser inventados.

Expressão-povo, quando toda escrita carrega junto outros tantos escritos, outras tantas tempestades de pensamento, marteladas ou lágrimas, expressas em blocos de anotações, receitas ou bulas de remédios. E por onde a escrita peregrinar, deixa sempre um pouco de suas chamas e segue inventando um povo à sua volta, expressando a potência de ser tanta. A escrita como expressão é antes uma experimentação com aquilo que se tem, com aquilo que se afeta, que pode ser mesmo um mínimo mundo afetante possível, mas ainda assim permite escrever e seguir preenchendo outros blocos de anotações, outros guardanapos ou papéis que são encontrados sonambulicamente em meio à noite. Experimentação que prolonga os movimentos em fluxo, que distende os sentidos, fazendo-os transbordar para além do que podem. Experimentação em sucessivo recomeço, pois que a paralisação é relançada ao desuso, já que não vigora quando a variação é contínua e incansável. Expressar como experimentação é o exercício de colocar-se em passagem, não em uma rota que traça um caminho pelo qual é possível voltar. A volta é sempre uma nova passagem, em nova paisagem, nunca se volta. Experimentam-se sempre novas idas.

A escrita é produção, portanto, quando as palavras não mais designam estados de coisas, nem manifestam um sujeito, um povo, alguém. Se assim fosse, seria ainda a escrita representativa, pessoal, localizada. Que ela crie, e não represente, instâncias como essas, populações que ainda não existem. Pois há alguma coisa irredutível a toda essa vontade de correspondência entre a escrita e esses mundos constituídos - pessoas, grupos, instituições. Algo que insiste e escreve-se sob a linguagem, margeando seus domínios. A expressão não é a possibilidade de manifestar e significar. Ela é essa dimensão sem a qual nenhuma proposição teria sentido (Deleuze, 1969/2007). É pela possibilidade de expressar, possibilidade de que algo tenha vazão pela linguagem, de que algo encontre nela um espaço a ser atravessado, experimentado, que toda manifestação e significação podem se dar.

A escrita tomada como expressão, portanto, insiste. E o que se expressa, através das singularidades liberadas, é o próprio sentido. Não há que procurá-lo alhures ou acima como fariam os decifradores platônicos de sentidos ocultos. O sentido está ali mesmo, pois é a própria experiência da expressão. Campo de escrita infinita e incorporal que faz também saltar pontos de inscrição onde o campo se corporifica, sempre incompleto, sempre arranhando o constituído, provocando-o à transformação. Escrever é, em certa medida, uma adivinhação, uma arte das superfícies: é buscar linhas e pontos singulares que se podem perseguir, acrescer, multiplicar nessa matéria sem espessura, neutra.

Como quando se pode observar fissuras da vida produzidas em um qualquer tecido inumano, ainda que advenha de um homem. Há ali o encontro com certo 
mapa estranho, sem indicações. Mapa que se perfaz nos movimentos e fluxos do vivo, que não representa nada, mas apresenta a criação em ato daquilo que são territórios de existência: "Assim, dividir o céu em secções e nele distribuir as linhas de vôos de pássaros, seguir sobre o solo o mapa que traça o focinho de um porco" (Deleuze, 1969/2007, p. 146). É nesse sentido que se adivinha, por seleção e seguimento, diferente de um místico transcendente. Pela derivação desde linhas constituídas, até encontrar aquelas fugidias, em direção ao território sem mapa. Linhas de secreção e odor, como as que demarcam territórios existenciais entre os animais, territórios por onde uma significação vem ser possível. Experiência e criação, assim, não servem uma à outra, mas aparecem como virtualmente simultâneas, quando a própria vida é o que está em criação constante. Ou ainda, vida engendrando linhas e campos de sua existência possível.

Falamos, portanto, de uma efetuação propriamente dita, que se dá no ato de escrita, bem como de algo que não se esgota nesse ato. Isso que permanece, por sua vez, circunscrevendo a escrita, impedindo seu esgotamento. Escrever subjacente, silêncio povoado e incorporal. Ambas as dimensões compõem a produção e remontam à eterna preparação do escrevente ${ }^{2}$ : são dias a fio em frente às teclas, à folha, ou onde mais as palavras possam aparecer. Como se ali elas já estivessem, ou quase, e faltasse apenas arrancá-las do estado informe. Tudo vale para que possam ser inscritas; todos os rituais são justificados nesse lançar-se cego em algo que margeia toda a possibilidade de escrever, que cutuca o corpo escrevente sem ponta e sem parada.

Escrever aparece então como uma prototortura a que se cedem os dedos, na ânsia de que o corpo dê passagem a algo de que não é dono. Atingido por uma ideia, esfumaçado por ela, vira-se logo o operador de conceitos da vida, sem restrição aos meios pelos quais se fará justiça com o que chega. O desaparecimento do eu, ou a sua irrelevância, é incontornável. O que é o escrevente aqui, senão uma constelação de impessoalidades que muito lhe concernem? Reunião do que chamamos singular, justamente. Mútuo roubo entre algo remoto de si, e aquilo que, todavia, o atinge como a mais ninguém.

Mais do que compreensão ou concordância intelectual, trata-se de ressonância, de um tom que prolifera. Se a literatura, como já dissemos, é a

2 Diferenciamos, aqui, escrevente e autor. Aquele, é quem está na prática da escrita, vive-a cotidianamente, mesmo que, efetivamente, nada escreva. Este é fiador de sua obra, identificado e reconhecido socialmente. Para mais, conferir Barthes (2005). exploração das margens, é por isso também um lugar privilegiado para se considerar o estatuto da experiência, ou seja, para revelar os processos de subjetivação, a constituição de novos modos de existência e possibilidades de vida. Radicalmente, é a descoberta de um pensamento como ato perigoso, sempre sem ação.

São os dobramentos de forças da subjetivação que se tornam legíveis na literatura, enquanto esta habita o espaço aberto da linguagem, através de suas experimentações. Afasta a linguagem de si mesma, e não a faz reencontrar-se com suas manifestações. Revela, mais uma vez, a vaziez constituinte do espaço literário. Assim, não é que o homem maneje a linguagem como a um instrumento, mas sim, que a habite, nunca totalmente. A verdade própria da linguagem, tendo um espaço aberto no lugar de um segredo, só pode ser a sua indefinida proliferação.

A escrita é um terreno onde deve se efetuar uma experiência de pensamento. Se assim não for, ela acaba por servir àquilo que restringe a proliferação da vida, nas suas mais variadas formas. Desde aí é possível conceber que a obra principal de quem escreve não são seus textos ou livros, mas o próprio movimento de escrevê-los, ou a vida que é provocada a transformar-se nesse processo, seja a sua, seja a de todos e qualquer um. Mais do que uma obra, ainda, parece querer durar o movimento provocado por um atravessamento, uma experiência de contato com o que pode e precisa ainda ser dito, sem que o seja para sempre ou de uma vez por todas. A fim de que a vida possa passar, ela que sempre segue, apesar das formas e dos conteúdos que a forçamos a tomar.

Essa escrita, que se propõe às margens do escrever, parece em princípio colocar-se em embate em relação à escrita acadêmica, no tanto que esta está ligada a formatos bastante definidos. Em outras palavras, ataca o que há de instituído, de bemintencionado e de acabado no escrever. Em relação a isso, sua proposta se assemelha a uma injeção de outro fluxo naquilo que parece estável. Acreditamos, todavia, que pode haver conversa e roubo entre as diferentes propostas de escrita, já que nenhuma delas é pura. Vale lembrar que este trabalho surge no ambiente acadêmico, problematizado a partir de leituras condizentes com um programa de estudos que, a certo ponto, fazem a escrita variar e andar por territórios inóspitos, de onde ela se alimenta para trazer novos ares à própria universidade. Uma frase de Deleuze pode sintetizar esse movimento, segundo o qual é uma experimentação o que se dá na escrita, mais do que o desvelo de significados obscuros, que adquirirão sentido segundo outros e ainda outros 
lugares de sentido. "Jamais interprete, experimente..." (Deleuze, 1992, p. 109), porque não queremos a repetição do mesmo, nem a posição de supremacia que vem com um saber que se impõe sobre o mundo, seja ele reconhecível, seja absurdamente exterior. Escrever apenas. Quando o que vive com mais força e intensidade está naquilo que não se sabe, que se soube e se esquece, naquilo que se nega em prol de uma afirmação que faz a vida mais potente, sempre em direção à maior abertura. "É na abnegação que toda afirmação termina" (Gide, 1917/1986, p. 158). E assim,

\section{escrever}

escrever

as auroras e mortes

chegadas das vidas

sem reescrever.

as rimas

ruídos calados

encantam

escrever pelo meio. os silêncios

os tempos que sobram nos entres

encontros continuam. sujos

belos

de cegueira e de súbito

corpo que deteriora

os rumos. a permanência

soluço

o grilo e os porcos

os dedos

a escrever

escrever.

\section{REFERÊNCIAS}

Barros, M. (2000). Ensaios fotográficos. Rio de Janeiro: Record.

Barthes, R. (2005). A preparação do romance II: a obra como vontade. São Paulo: Martins Fontes.

Blanchot, M. (2001). A Conversa infinita. São Paulo: Ed. Escuta. (Original publicado em 1953).

Blanchot, M. (2005). O livro por vir. São Paulo: Martins Fontes. (Original publicado em 1959).

Deleuze, G. (1988). Foucault. São Paulo: Ed. Brasiliense.

Deleuze, G. (1992). Conversações, 1972 - 1990. Rio de Janeiro: Ed. 34.

Deleuze, G. (1997). Crítica e clínica. São Paulo: Ed. 34.

Deleuze, G. (2007). Lógica do sentido. São Paulo: Perspectiva. (Original publicado em 1969).

Deleuze, G., \& Parnet, C. (1998). Diálogos. São Paulo: Ed. Escuta.

Foucault, M. (1990). O pensamento do exterior. São Paulo: Princípio Editora.

Gide, A. (1986). Os frutos da terra. Rio de Janeiro: Editora Rio Gráfica. (Original publicado em 1917).

Miller, H. (1964). Writing is its own reward. A turning point in my life. In Thomas H. Moore (Org.), Henry Miller on writing (21a ed.) (pp.100-105). Nova Iorque: New Directions Publishing Corporation.

Pellejero, E. (2008). Literatura e fabulação: Deleuze e a política da expressão. Polymatheia. Revista de Filosofia, 5(4), 61-78.

Recebido em 14/06/2011

Aceito em 15/03/2012
Endereço para correspondência:
Tania Mara Galli Fonseca. Rua Campos Salles, 262, Bairro Boa Vista, CEP 90480-030, Porto Alegre -RS, Brasil.E-mail: tfonseca@via-rs.net. 